\title{
Accelerated atrioventricular conduction after myocardial infarction. A study using His bundle electrograms
}

Sir:

I am writing to object against the publication of the paper of Mathew and Raftery, British Heart fournal, 1973, 35, 985 .

The paper is based on a gross misconception that the normal AH value is $120-200 \mathrm{msec}$. The authors, therefore, consider a value of $100 \mathrm{msec}$ at a heart rate of 68 as a sign of accelerated nodal conduction. In fact, the normal $\mathrm{AH}$ value is $80-140 \mathrm{msec}$ and therefore the $\mathrm{AH}$ data of Table I are perfectly normal. Were one to assume an $\mathrm{AH}$ of $200 \mathrm{msec}$ as normal, adding to this the normal HV conduction (correctly stated in the paper as $35-55 \mathrm{msec}$ ) would bring up the normal AV (i.e. PR) conduction to $255 \mathrm{msec!}$

Fig. 2 illustrates the His electrograms during atrial pacing. 'Note the short AH and HV interval' says the legend; yet $A$ is not marked in the Figure, and where it is is anybody's guess. Furthermore, this Figure is supposed to compare lead III with the His electrogram; but lead III in Case I (Fig. I) looks completely different!

The normal AH data in Table I make complete nonsense of the discussion 'that the normal delay process in the AV node has been destroyed'. In fact the AH distances with 100 and $120 \mathrm{msec}$ at a rate of 68 and 100, respectively, are normal and so is the AH delay with pacing. The slight acceleration of HV conduction may be an irritative phenomenon of the bundle of His shortly after posterior infarct.

The second Case (Fig. 4) shows a normal AH distance (erroneously designated as $\mathrm{PH}$ !) of all the three complexes; the HV distance is abolished in the third complex. The criterion of Wolff-ParkinsonWhite, the bypass of the AV node by an accessory bundle, does not exist as this should considerably reduce the $\mathrm{AH}$ distance which is normal in the abnormal complex. The correct interpretation here is that of a lower junctional extrasystole appearing as a trigeminus with aberrant ventricular conduction (e.g. bundle-branch block).

$$
\begin{aligned}
& \text { Cornelio Papp, } \\
& 75 \text { Regency Lodge, } \\
& \text { Adelaide Road, } \\
& \text { London NW3 5EB. }
\end{aligned}
$$

Sir:

The problem of pre-excitation in association with myocardial infarction has attracted considerable interest and any contribution to its understanding is to be welcomed. We are ourselves investigating factors that may influence the behaviour of preexisting extranodal bypasses, and myocardial infarction is clearly one of the important conditions that requires consideration. Shortening of the PR interval has been recognized to follow myocardial infarction (Scherf and Cohen, 1964) and is usually though not always transient: however, the mechanisms remain to be clarified. We do not, however, feel that the report by Mathew and Raftery is a positive contribution to this topic and wish to raise a few points that are, we consider, crucial, and that cast considerable doubt on the validity of their study.

In their first case the $\mathrm{AH}$ time was measured from the onset of the $P$ wave on the surface electrocardiogram, and the normal AH time was said to be 120-200 msec. On this basis the authors considered that the AH time was abbreviated, being $100 \mathrm{msec}$ at 68 beats a minute. We would be interested in the source for these 'normal' values. Damato et al. (1969) quote the normal PH time ( $\mathrm{AH}$ time using the authors' terminology) as $80-140 \mathrm{msec}$ for rates below 80 beats a minute, and Narula et al. (1970) give the lower limit of normal for PA as $25 \mathrm{msec}$ 
and for $\mathrm{AH}$ as $50 \mathrm{msec}$, indicating a lower limit of normal for the $\mathrm{PH}$ time (again $\mathrm{AH}$ as used by Mathew and Raftery) of $75 \mathrm{msec}$; these normal values accord with those found in our own laboratory, and with those of Puech, Coumel, and Touboul (1972). It therefore appears that the AV nodal conduction time in Case I is not abbreviated at rest, but is normal. We also consider that the prolongation of $\mathrm{AH}$ time with atrial pacing is within normal limits, the lowest value being 202 msec at a pacing rate of 150 beats a minute in the series reported by Damato et al. (1969). The HV time is indeed short and can only be explained either by accelerated conduction in the His-Purkinje system below the AV node, or possibly by a partial bypass of the AV node inserting low in the bundle of His.

A more plausible explanation for the findings is that there was transient PR lengthening due to firstdegree AV nodal block complicating inferior infarction. With recovery, the PR interval could have returned to its previous state and, in the absence of a tracing showing that the PR interval had been normal before the infarct, this seems to us to be a much more likely situation.

In their second case, the diagnosis of intermittent Wolff-Parkinson-White type conduction is suggested because of premature beats demonstrated in Fig. 3. These are not atrial extrasystoles but could represent late diastolic ventricular extrasystoles, which can mimic the Wolff-Parkinson-White syndrome (Bellet, 1971; Schamroth, 1971). Even granting the occurrence of intermittent pre-excitation, its relation to the cardiac infarct is again unsubstantiated, and by no means exclusively explained by their thesis.

Careful consideration of explanations for any findings reported is mandatory, and we do not believe that this has been done by Drs. Mathew and Raftery.

Dennis Krikler,
Cardiovascular Division,
Royal Postgraduate Medical School,
London WI2.

Roworth Spurrell, Department of Cardiology, Guy's Hospital, London SEI.

\section{References}

Bellet, S. (1971). Clinical Disorders of the Heart Beat, 3rd ed., p. 299. Lea and Febiger, Philadelphia.

Damato, A. N., Lau, S. H., Helfant, R. H., Stein, E., Berkowitz, W. D., and Cohen, S. I. (1969). Study of atrio- ventricular conduction in man using electrode catheter recordings of His bundle activity. Circulation, 39, 287.

Narula, O. S., Cohen, L. S., Samet, P., Lister, J. W., Scherlag, B., and Hildner, F. J. (1970). Localization of A-V conduction defects in man by recording of the His bundle electrogram. American fournal of Cardiology, 25, 228.

Puech, P., Coumel, Ph., and Touboul, P. (I972). L'activité du tissu de conduction auriculo-ventriculaire en électrocardiographie endocavitaire. Actualités Cardio-Vasculaires Médico-Chirurgicales, 6, 69.

Schamroth, L. (1971). The Disorders of Cardiac Rhythm, p. 372. Blackwell Scientific Publications, Oxford and Edinburgh.

Scherf, D., and Cohen, J. (1964). The Atrioventricular Node and Selected Cardiac Arrhythmias, p. 98. Grune and Stratton, New York.

These letters were shown to Dr. Raftery who replies as follows.

Sir:

Thank you for an opportunity to reply to these critical letters. Both Dr. Papp and Drs. Spurrell and Krikler have misinterpreted the figures given in our Table entitled 'Measured electrogram intervals during atrial pacing'. These values indicate the range of $\mathrm{AH}$ interval which might be expected on increasing the heart rate from $68 / \mathrm{min}$ to $170 / \mathrm{min}$ and not the 'normal' range of $\mathrm{AH}$ interval in the 'resting' heart. We are aware of the value for prolongation of the $\mathrm{AH}$ interval with increasing heart rates by atrial pacing published by Damato et al. (1969) but we considered the number of patients (II) and the number of pacing rates (only 2 at $150 / \mathrm{min}$ and none above this rate) insufficient to provide an adequate standard. We based our 'normal' values on results obtained from 60 studies on 40 patients with angina pectoris but with no documented evidence of myocardial infarction who underwent atrial pacing studies in our laboratory.

Clearly, we should have detailed these studies in the text, but we considered our meaning to be clear. This misunderstanding is compounded by a misprint which we overlooked when proof reading; the 'normal' range for $\mathrm{AH}$ interval during atrial pacing should read 120-300 msec and this is referred to in the text. The plausible explanation offered by Drs. Spurrell and Krikler for the short HV interval in the patient could well be correct, but is even more speculative than our own explanation.

Dr. Papp is quite correct to point out our failure to label the pacing artefact in Fig. 2, but I am sure that he does himself an injustice when he suggests that he could not identify this on the tracing without a label. Furthermore, we feel sure that he recognizes that the difference in the lead III complexes arises because the pacing impulse falls on the Twave, thereby producing a $\mathrm{P}$-on- $\mathrm{T}$. 
Lower junctional extrasystoles appearing as trigeminus with aberrant ventricular conduction is not a likely explanation for the second patient, since each abnormal complex is preceded by a short HV interval. Depending upon the anatomy of the conduction anomaly, a normal AH interval is possible in the Wolff-Parkinson-White syndrome (Castellanos, Castillo, and Agha, 197I) and does not rule out this diagnosis. The fact that each ventricular complex is clearly preceded by a His complex makes the suggestion of late diastolic ventricular ectopics unlikely, though it does not rule it out.

Since this paper was written both patients have died. Unfortunately, only the heart of the second patient was available for postmortem studies, and the results of detailed histology of the conducting system are still awaited. We will be happy to communicate the results to our critics should they be anxious to see them.

E. B. Raftery,

Northwick Park Hospital, Watford Road,

Harrow, Middlesex HAI $3 \mathrm{UJ}$.

\section{Reference}

Castellanos, A., Castillo, C. A., and Agha, A. S. (1971). Contribution of His bundle recordings to the understanding of clinical arrhythmias. American fournal of Cardiology, 28, 499. 